\title{
Effects of four types of integrated Chinese and Western medicines for the treatment of COVID-19 in China: a network meta-analysis
}

\author{
Lairun Jin \\ (iD) Yan $X u^{1}$ \\ (iD) Hui Yuan ${ }^{2}$
}

1. Office of Educational Administration, the First Affiliated Hospital of Wannan Medical College (Yijishan Hospital of Wannan Medical College), Wuhu 241001, Anhui, China. 2. School of Public Health, Wannan Medical College, Wuhu 241001, Anhui, China.

\section{SUMMARY}

OBJECTIVE: Various integrated Chinese and Western medicines might be beneficial for the treatment of Coronavirus disease 2019 (COVID19). This study aims to evaluate the efficacy of lung computed tomography (CT) of four integrated Chinese and Western medicines in the treatment of COVID-19 using network meta-analysis (NMA).

METHODS: Multiple databases were consulted to find randomized controlled trials of four different types of integrated Chinese and Western medicines for the treatment of COVID-19. NMA was conducted on the data using Stata (13.0) software. The odds ratio (OR) was calculated. The studies included in this paper were divided into a control group (Western medicine) and an observation group (one of four integrated Chinese and Western medicines).

RESULTS: 5 eligible publications were identified. A total of 598 cases were included in the study, and the results showed that the four types of integrated Chinese and Western medicines (symptomatic and supportive care with Qingfei Touxie Fuzheng, Lianhua Qingke, and Xuebijing) were significantly superior $(P<0.05)$ to symptomatic and supportive care alone, except for symptomatic and supportive care with Lianhua Qingwen. The combination of symptomatic and supportive care with Lianhua Qingke had the highest probability of being the most clinically efficacious intervention, with a surface under the cumulative ranking (SUCRA) curve of 85.7.

CONCLUSIONS: A combination of symptomatic and supportive care with Lianhua Qingke is the best option among the four integrated Chinese and Western medicines considered for the treatment of COVID-19.

KEYwORDS: Coronavirus Infections. Coronavirus. Medicine, Chinese Traditional. Drugs, Chinese Herbal. Meta-Analysis.

\section{INTRODUCTION}

The coronavirus disease 2019 (COVID-19) is an acute respiratory-tract-based clinical syndrome caused by a new coronavirus, which is currently widespread on a global scale. The infectious disease seriously endangers human health and public safety, and this damage continues to increase every day ${ }^{1}$. Clinicians mainly use symptomatic support therapy since there is currently no specific medicine that can be used to cure the disease. Some studies have shown that the combination of Chinese and Western medicine can

DATE OF SUBMISSION: 23-May-2020

DATE OF ACCEPTANCE: 23-May-2020

CORRESPONDING AUTHOR: Yan Xu

School of Public Health, Wannan Medical College, No. 22 Road of Wenchangxi - Wuhu - 241002 - Anhui, China - Tel: 86+13955362912

E-mail: yuanhui0553@126.com 
achieve some effect on the treatment of COVID-192.

A network meta-analysis (NMA) is a meta-analysis that combines traditional direct/head-to-head comparison and indirect comparison. Traditional meta analysis (TMA) focuses on comparing two groups, while NMA emphasizes comparing multiple interventions under the same conditions based on its high statistical power and precision, so it is also called multiple treatments meta-analysis ${ }^{3}$.

The aim of this study was to evaluate the lung computed tomography (CT) efficacy of four types of integrated Chinese and western medicines in the treatment of COVID-19 using NMA and rank them according to their performance. Combinations included symptomatic and supportive care with Qingfei Touxie Fuzheng recipe, Lianhua Qingwen granule, Lianhua Qingke granule, and Xuebijing injection. This study may provide a useful guide for the selection of medication treatments for COVID-19.

\section{METHODS}

\section{Search Strategy}

The databases used for this study included PubMed, EMBASE, Web of Science, SciFinder and Sino Med, Cochrane Library, BIOSIS Previews, China National Knowledge Index, China Biomedical Medicine, Wan fang, Chinese Science Citation, Chongqing VIP Network, China Science and Technology Journal, and China Academic Journal Network Publishing. The search words used included Chinese medicine, combination therapy, Qingfei Touxie Fuzheng, Lianhua Qingwen, Lianhua Qingke, Xuebijing, efficacy, drug therapy, randomized controlled trials, pneumonia, and coronavirus disease 2019.

\section{Inclusion and Exclusion Criteria}

The inclusion criteria were as follows: (1) randomized controlled trials; (2) patients with COVID-19 who met the criteria of Coronavirus disease 2019 diagnosis, and the treatment plan (6th edition) of the Chinese National Health Commission ${ }^{4}$; (3) patients aged 18 years and above; (4) provision of an effective number of cases for measurement of outcomes; (5) studies that used symptomatic and supportive care ${ }^{4}$ as the control group, while the observation group was one of the integrated Chinese and Western medicines for the treatment of COVID-19.

The exclusion criteria were as follows: (1) studies with incomplete or repeated data; (2) purely descriptive studies with no control group; (3) research types that were summaries of experience, theoretical discussions, case reports, animal-based experiments, and reviews; (4) patients with dementia or severe mental illness; (5) patients with severe liver, kidney, or heart damage, tumor, or autoimmune disease.

\section{Efficacy Evaluation Criteria}

The curative effect in this study was based on lung computed tomography (CT) findings. The total effective cases were defined as the number of patients whose pulmonary lesions had significant change or progression compared with the previous CT.

\section{Data Extraction and Quality Evaluation}

Two reviewers searched the literature and extracted data independently based on the exclusion and inclusion criteria. The contents of extracted data included the following: (1) basic information of the publication; (2) outcome indicators of CT findings; (3) quality indicators of the publication. Disagreements were resolved through discussion with a third evaluator. The Jadad quality scoring standard was used to evaluate the quality of the publications.

\section{Statistical Analysis}

Commands of the network package in Stata (13.0) were used to construct the network, evidence contribution, confidence interval (CI), funnel, and ranking plots. The efficacy of interventions was ranked according to the value of the surface under the cumulative ranking (SUCRA) curve. The selected indicators were count data, while OR was used as the combined effect, and the confidence interval (CI) was set at $95 \%$. A P-value $<0.05$ was defined as statistically significant.

\section{Ethics statement}

All analyses were adapted from previously published work. Thus, no ethical approval and patient consent were required.

\section{RESULTS}

\section{Characteristics of Included Studies}

A total of 5 randomized controlled trials involving 598 patients were ultimately included in this study ${ }^{5-9}$. Figure 1 shows the selection details of the studies included, while their basic information is presented in Table 1. 
FIGURE 1. FLOW DIAGRAM OF THE SELECTION DETAILS OF INCLUDED PUBLICATIONS.

67 publications identified through database search

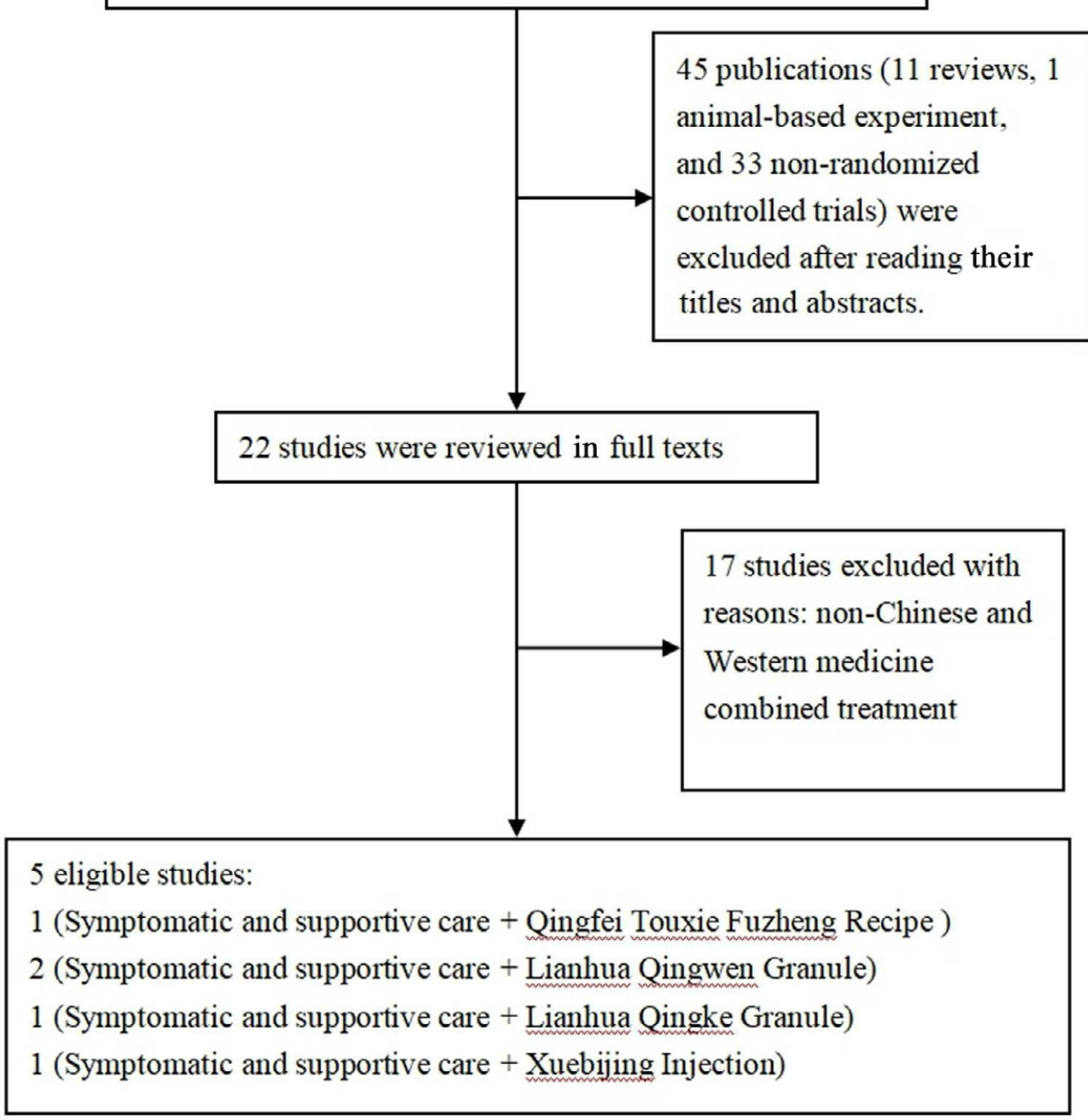

TABLE 1. BASIC INFORMATION OF STUDIES INCLUDED IN THE NETWORK META-ANALYSIS

\begin{tabular}{|c|c|c|c|c|c|c|c|c|c|c|c|}
\hline \multirow[t]{2}{*}{ Author } & \multirow[t]{2}{*}{ Year } & \multirow{2}{*}{$\begin{array}{l}\text { Com- } \\
\text { pari- } \\
\text { son }\end{array}$} & \multirow[t]{2}{*}{$\begin{array}{l}\text { Coun- } \\
\text { try }\end{array}$} & \multicolumn{5}{|c|}{$\begin{array}{l}\text { Simple size (Total effective cases/Total } \\
\text { cases) }\end{array}$} & \multirow{2}{*}{$\begin{array}{l}\text { Dose } \\
\text { Combined Chinese medicine }\end{array}$} & \multirow{2}{*}{$\begin{array}{l}\text { Dura- } \\
\text { tion } \\
\text { (Days) }\end{array}$} & \multirow{2}{*}{$\begin{array}{l}\text { Jadad } \\
\text { quality } \\
\text { score }\end{array}$} \\
\hline & & & & A & B & C & D & $\mathrm{E}$ & & & \\
\hline Ding et al. ${ }^{5}$ & 2020 & $B$ vs $A$ & China & $21 / 49$ & $32 / 51$ & - & - & - & 150 milliliters each time, 2 times a day & 10 & 3 \\
\hline Cheng et al. ${ }^{6}$ & 2020 & C vs A & China & $23 / 51$ & - & $28 / 51$ & - & - & 6 grams each time, 3 times a day & 7 & 2 \\
\hline Yu et al. ${ }^{7}$ & 2020 & C vs A & China & $93 / 148$ & - & $102 / 147$ & - & - & 6 grams each time, 3 times a day & 7 & 3 \\
\hline Sun et al. ${ }^{8}$ & 2020 & D vs $A$ & China & $18 / 25$ & - & - & $31 / 32$ & - & 1 bag each time, 3 times a day & 14 & 3 \\
\hline Zhang et al. ${ }^{9}$ & 2020 & Evs A & China & $15 / 22$ & - & - & - & $21 / 22$ & 50 milliliters each time, 2 times a day & 7 & 1 \\
\hline
\end{tabular}

Notes: A, Symptomatic and supportive care; B, Symptomatic and supportive care + Qingfei Touxie Fuzheng Recipe; C, Symptomatic and supportive care + Lianhua Qingwen Granule; D, Symptomatic and supportive care + Lianhua Qingke Granule; E, Symptomatic and supportive care + Xuebijing Injection.

Network Meta-analysis

Network Plot of Four Types of Integrated Chinese and Western Medicines

Of the 5 studies, publications on the combination of symptomatic and supportive care with Lianhua
Qingwen were the most frequent. The group of symptomatic and supportive care alone had the highest number of subjects, while symptomatic and supportive care + Xuebijing had the lowest number of subjects (Figure 2). 
FIGURE 2.NETWORK PLOT OF DIFFERENT

INTERVENTIONS FOR TREATMENT OF MYCOPLASMA PNEUMONIA IN CHILDREN.

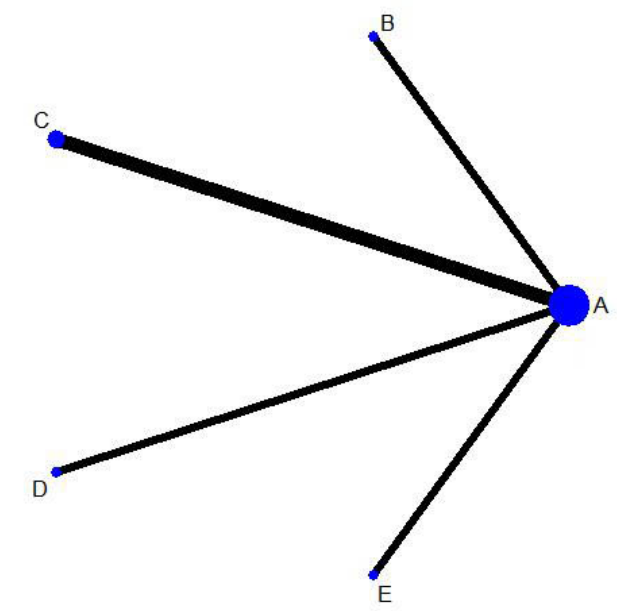

The size of the point in the network graph is proportional to the number of subjects, while the thickness of the line is proportional to the number of studies. Abbreviations: A, Symptomatic and supportive care; B, Symptomatic and supportive care + Qingfei Touxie Fuzheng Recipe; C, Symptomatic and supportive care + Lianhua Qingwen Granule; D, Symptomatic and supportive care + Lianhua Qingke Granule; E, Symptomatic and supportive care + Xuebijing Injection.

\section{Evidence Contribution Plot}

Figure 3 shows that the direct comparison of symptomatic and supportive care alone and the combination of symptomatic and supportive care with Qingfei Touxie Fuzheng had a 100 \% effect on the mixed comparison. The direct comparison between symptomatic and supportive care alone and symptomatic and supportive care + Qingfei Touxie Fuzheng had a 50 \% effect on the indirect comparison between symptomatic and supportive care + Qingfei Touxie Fuzheng, and symptomatic and supportive care + Lianhua Qingwen. The direct comparison of symptomatic and supportive care alone and symptomatic and supportive care + Qingfei Touxie Fuzheng had a $25.0 \%$ effect on the results of the meta-analysis.

\section{Confidence Interval (Cl) Plot}

The meta-analysis results showed that the pooled OR and 95\% CI of COVID-19 improvement compared with symptomatic and supportive care alone was 2.25 (1.01 to 5.01) for symptomatic and supportive care + Qingfei Touxie Fuzheng, 1.38 (0.91 to 2.08) for symptomatic and supportive care + Lianhua Qingwen, 12.06 (1.37 to 106.04) for symptomatic and supportive care + Lianhua Qingke, and 9.80 (1.09 to 88.23) for
FIGURE 3. EVIDENCE CONTRIBUTION PLOT.

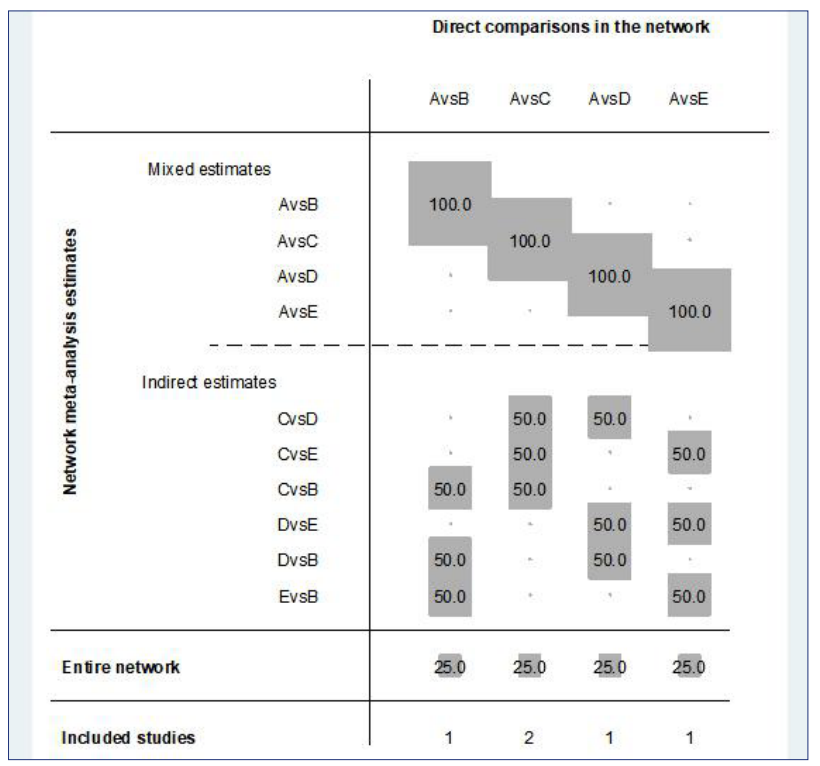

The matrix showed the effect of comparing the results of different control measures directly against the results of their network meta-analysis. Abbreviations: A, Symptomatic and supportive care; B, Symptomatic and supportive care + Qingfei Touxie Fuzheng Recipe; C, Symptomatic and supportive care + Lianhua Qingwen Granule; D, Symptomatic and supportive care + Lianhua Qingke Granule; E, Symptomatic and supportive care + Xuebijing Injection.

symptomatic and supportive care + Xuebijing, which indicates a significant difference in lung CT efficacy, except for symptomatic and supportive care + Lianhua Qingwen. For the comparison between Chinese and western combinations, no significant differences were found. The OR for the network estimates along with 95\% CI is presented in Figure 4.

\section{Publication Bias}

Regarding publication bias, all the outcomes in the study were almost symmetrical (Figure 5), indicating that the publication bias may not have existed.

TABLE 2. SUCRA RANKINGS OF MYCOPLASMA PNEUMONIA IN CHILDREN TREATMENTS

\begin{tabular}{l|l|l|l} 
Treatment & \multicolumn{1}{l}{ SUCRA } & Pr Best & Mean rank \\
A & 0.0 & 0.0 & 4.9 \\
\hline B & 50.5 & 1.2 & 3.0 \\
\hline C & 28.8 & 0.1 & 3.8 \\
\hline D & 85.7 & 54.0 & 1.6 \\
\hline E & 82.1 & 44.7 & 1.7 \\
\hline
\end{tabular}

Notes: A, Symptomatic and supportive care; B, Symptomatic and supportive care + Qingfei Touxie Fuzheng Recipe; C, Symptomatic and supportive care + Lianhua QinQingei Touxie Fuzheng Recipe; C, Symptomatic and supportive care + Lianhua Qin-
gwen Granule; D, Symptomatic and supportive care + Lianhua Qingke Granule; E, gwen Granule; D, Symptomatic and supportive care +
Symptomatic and supportive care + Xuebijing Injection. 


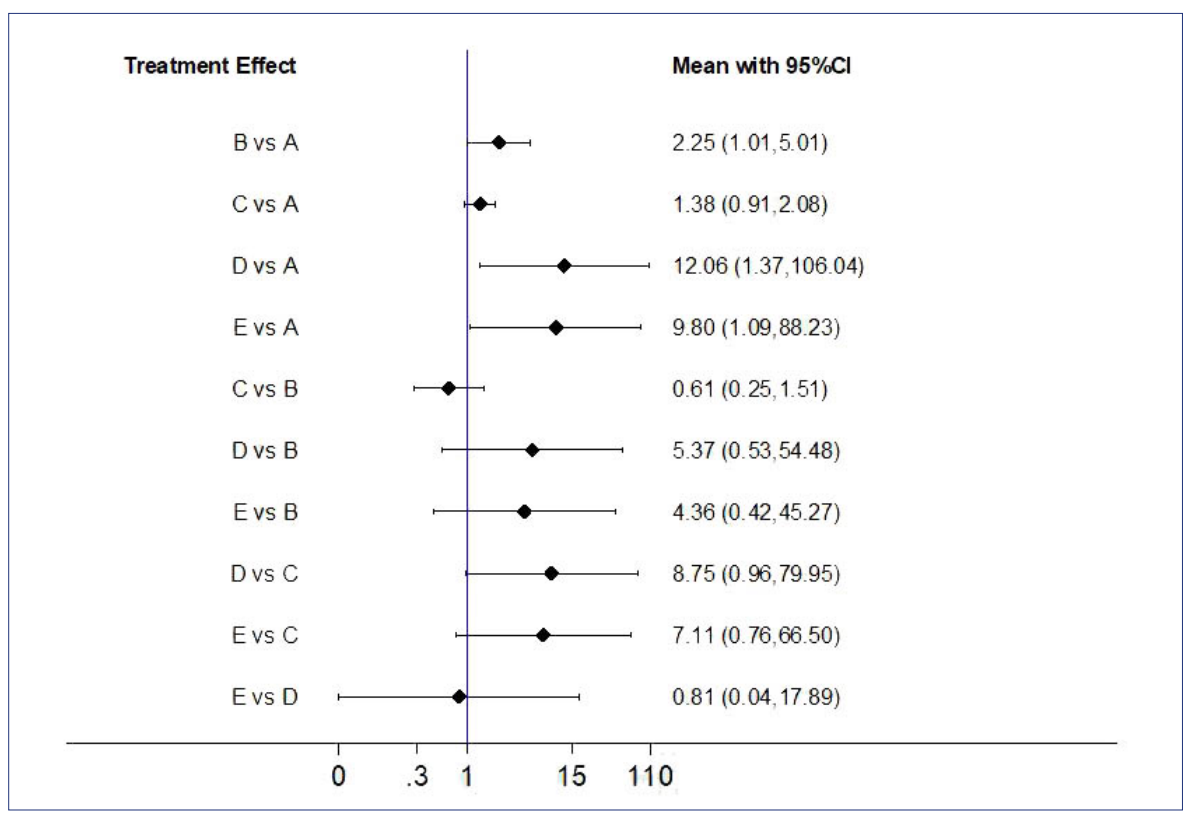

FIGURE 4. FNETWORK

ESTIMATES OF MEAN

OR, THEIR $95 \%$ CIS AND

PREDICTION INTERVALS.

Abbreviations: Prl, prediction intervals; A, Symptomatic and supportive care; B, Symptomatic and supportive care + Qingfei Touxie Fuzheng Recipe; C, Symptomatic and supportive care + Lianhua Qingwen Granule; D, Symptomatic and supportive care + Lianhua Qingke Granule; E, Symptomatic and supportive care + Xuebijing Injection.

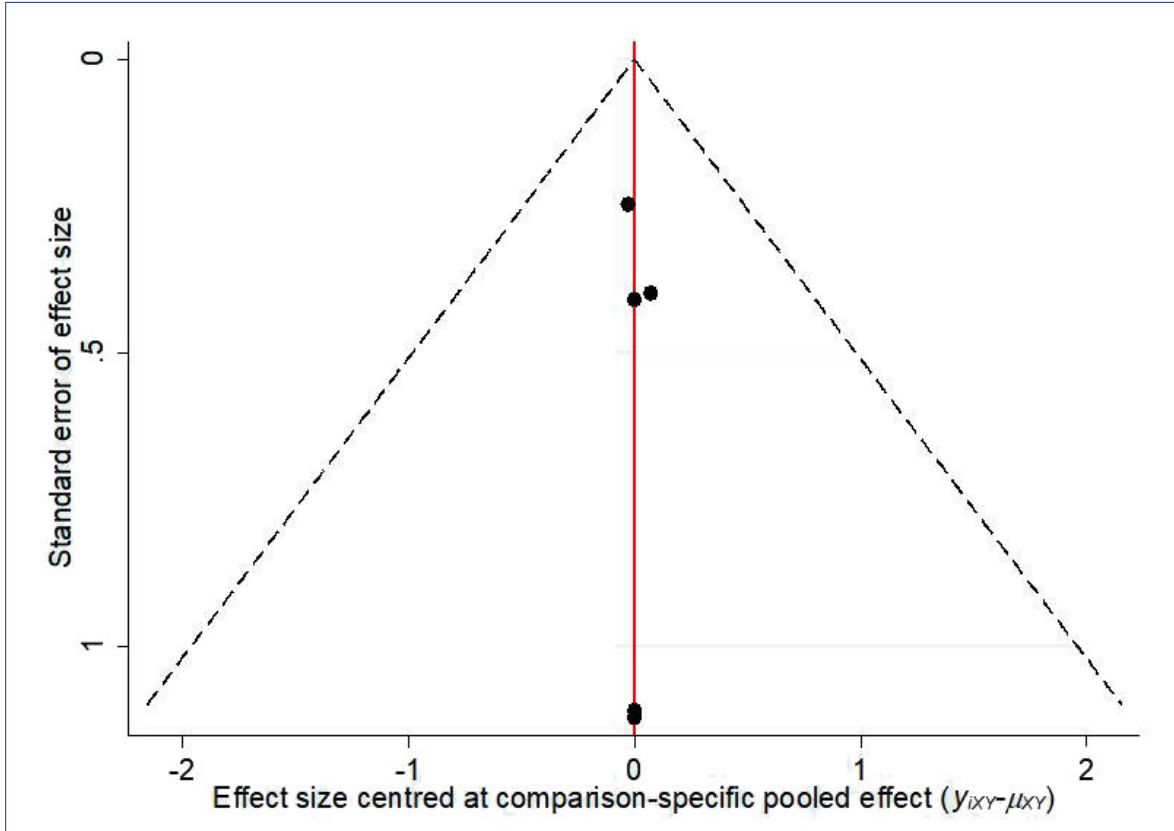

FIGURE 5. FUNNEL PLOT FOR PUBLICATION BIAS IN SELECTED STUDIES.

Abbreviations: A, Symptomatic and supportive care; B, Symptomatic and supportive care + Qingfei Touxie Fuzheng Recipe; C, Symptomatic and supportive care + Lianhua Qingwen Granule; $D$, Symptomatic and supportive care + Lianhua Qingke Granule; E, Symptomatic and supportive care + Xuebijing Injection.

\section{Ranking Plot}

The distribution of probabilities for each treatment ranked for their efficacy in COVID-19 according to SUCRA values are shown in Figure 6 and Table 2. The order of SUCRA values for different types of integrated Chinese and Western medicines was as follows: symptomatic and supportive care + Lianhua Qingke (85.7), symptomatic and supportive care + Xuebijing (82.1), symptomatic and supportive care + Qingfei Touxie Fuzheng (50.5), and symptomatic and supportive care + Lianhua Qingwen (28.8). Therefore, the combination of symptomatic and supportive care with Lianhua Qingke had the highest probability of being the best intervention option in terms of lung CT efficacy.

\section{DISCUSSION}

This study analyzed four types of integrated Chinese and Western medicines and conducted a pairwise comparison. The resulting network plot makes the results more intuitive. The results showed that the combination of symptomatic and supportive care with Qingfei Touxie Fuzheng, Lianhua Qingke, and Xuebijing was more effective when compared to symptomatic and supportive care alone in the treatment of COVID-19. The combination of symptomatic and supportive care with Lianhua Qingke had the highest SUCRA value and the highest probability of being the best treatment option. 


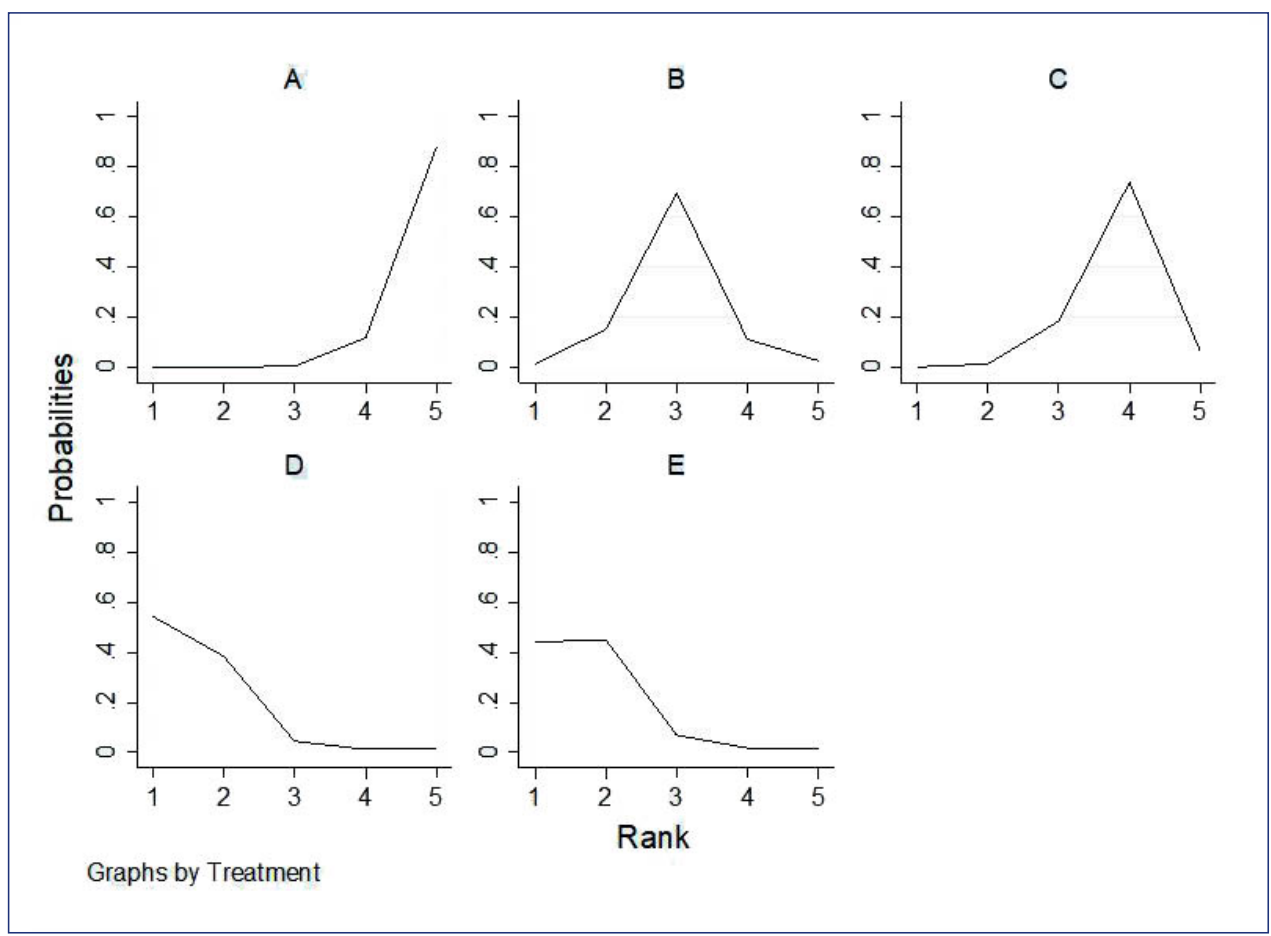

FIGURE 6. SUCRA FOR

THE CUMULATIVE

PROBABILITIES.

Abbreviations: A, Symptomatic and supportive care; $B$, Symptomatic and supportive care + Qingfei Touxie Fuzheng Recipe; C, Symptomatic and supportive care + Lianhua Qingwen Granule; D, Symptomatic and supportive care + Lianhua Qingke Granule; E, Symptomatic and supportive care + Xuebijing Injection.

As the COVID-19 epidemic continues to spread, the respiratory infectious disease poses a serious threat to human health and is characterized by high infectivity. Fever, dry cough, and fatigue are the main clinical manifestations of COVID-19 in patients ${ }^{10}$. Pathological anatomy shows the formation of mucus and mucus plugs in the bronchial lumen, and the formation of serous, fibrinous exudate and transparent membrane in the alveolar cavity ${ }^{11}$. These viscous exudates obstruct the airways and are difficult to be coughed out, seriously affecting the ventilation function of the lungs, reducing the efficacy of oxygen therapy and mechanical ventilation, and even causing suffocation and death ${ }^{11}$. In the early stage of COVID19 , the lungs show multiple small patchy shadows and interstitial changes, especially in the extrapulmonary zone. Then it develops multiple ground glass shadows and infiltration shadows. In severe cases, lung consolidation may occur, and pleural effusions are rare $^{11}$.

For clinical treatment, no specific drugs have been found. At present, Western medicine mainly adopts symptomatic supportive treatments such as anti-virus, oxygen therapy, and nutritional support ${ }^{4}$. Chinese medicine has a long history in epidemic treatment and has accumulated rich clinical experience, such as outstanding contributions to the outbreak of Severe acute respiratory syndrome (SARS) ${ }^{12}$.

Respiratory mucus or phlegm belongs to the category of "phlegm" in traditional Chinese medicine $^{8}$. Lianhuaqingke granule is an innovative Chinese medicine developed under the guidance of this Chinese medicine theory during the outbreak of the new coronavirus pneumonia ${ }^{8}$. The combination of symptomatic and supportive care with Lianhua Qingke had the highest probability of being the best intervention option in terms of lung CT efficacy, indicating that Lianhua Qingke has a better improvement effect on the lung deterioration. Lianhua Qingke is composed of ephedra, gypsum, forsythia, mulberry skin, fried bitter almond, honeysuckle, rhubarb, and platycodon grandiflorum, which have the function of clearing away heat and detoxifying, clearing the lungs, and relieving fever, cough, and phlegm. Lianhuaqingke can block the cascade reaction chain with airway inflammation as the core while antiviral and bacteriostatic drugs regulate immune function, relieve airway spasm, protect airway mucosa, reduce airway resistance, and improve respiratory function. In addition, no adverse events related to Lianhua Qingke have been found ${ }^{8}$.

This study may be very helpful for the clinical treatment of COVID-19, and its limitations include the following: (1) the number of publications included in this paper is small; (2) lack of uniformity in the duration of treatment; and (3) there is no quantitative analysis of clinical symptoms or immune system cytokines. Future studies involving a large sample size 
and high-quality RCT are needed in the treatment of COVID-19.

\section{Sources of Funding \\ None.}

\section{Conflict of interest}

All authors have no conflicts of interest to declare and have approved the submitted manuscript and are responsible for the reported research. Approval from the Research Ethics Committee is not applicable to this study.

\section{Authors' contributions}

Lairun Jin was responsible for the concept and design of the manuscript. Hui Yuan and Yan Xu were responsible for data collection. Lairun Jin and Hui Yuan were responsible for the analysis and interpretation of data. Lairun Jin and Yan Xu were responsible for the writing and revision. All authors approved the final version of the submitted manuscript.

\section{Acknowledgment}

Special thanks to Miss Wang XR for bringing me good luck.

\section{RESUMO}

OBJETIVO: Vários medicamentos chineses e ocidentais integrados podem ser benéficos para o tratamento da COVID-19. O objetivo deste estudo é avaliar a eficácia da tomografia computadorizada (TC) de pulmão de quatro medicamentos chineses e ocidentais integrados para o tratamento da COVID-19 usando uma meta-análise em rede (NMA).

MÉTODOS: Vários bancos de dados foram consultados para encontrar ensaios clínicos randomizados de quatro tipos diferentes de medicamentos chineses e ocidentais integrados para o tratamento da COVID-19. A NMA foi realizada nos dados usando o software Stata (13.0). O odds ratio (OR) foi calculado. Os estudos incluídos neste artigo foram divididos em um grupo de controle (medicina ocidental) e um grupo de observação (um dos quatro medicamentos chineses e ocidentais integrados).

RESULTADOS: 5 publicações elegíveis foram identificadas. Um total de 598 casos foram incluídos no estudo, e os resultados mostraram que os quatro tipos de medicamentos chineses e ocidentais integrados (tratamento sintomático e de suporte com Qingfei Touxie Fuzheng, Lianhua Qingke e Xuebijing) foram significativamente superiores $(P<0,05)$ a somente cuidados sintomáticos e de suporte, exceto cuidados sintomáticos e de suporte com Lianhua Qingwen. A combinação de cuidados sintomáticos e de suporte com Lianhua Qingke teve a maior probabilidade de ser a intervenção clinicamente mais eficaz, com uma superfície abaixo da curva de classificação cumulativa (SUCRA) de 85,7.

CONCLUSÕES: Uma combinação de tratamento sintomático e de suporte com Lianhua Qingke é a melhor opção entre os quatro medicamentos integrados chineses e ocidentais considerados para o tratamento de COVID-19.

PALAVRAS-CHAVE: Infecções por Coronavirus. Coronavirus. Medicina Tradicional Chinesa. Medicamentos de Ervas Chinesas. Metanálise.

\section{REFERENCES}

1. Vaira LA, Salzano G, Petrocelli M, Deiana G, Salzano FA, De Riu G. Validation of a self-administered olfactory and gustatory test for the remotely evaluation of COVID-19 patients in home quarantine. Head Neck. 2020. doi: 10.1002/hed.26228.

2. Zhang L, Yu J, Zhou Y, Shen M, Sun L. Becoming a faithful defender: traditional Chinese medicine against coronavirus disease 2019 (COVID-19). Am / Chin Med. 2020:1-15.

3. Bahji A, Ermacora D, Stephenson C, Hawken ER, Vazquez G. Comparative efficacy and tolerability of pharmacological treatments for the treatment of acute bipolar depression: a systematic review and network meta-analysis. J Affect Disord. 2020;269:154-84.

4. National Health Commission of the People's Republic of China. Diagnosis and treatment plan of corona virus disease 2019 (tentative sixth edition). Glob Health J. 2020;10.1016/j.glohj.2020.03.001. doi:10.1016/j. glohj.2020.03.001.

5. Ding X, Zhang Y, He D, Zhang M, Tan Y, Yu A, et al. Clinical effect and mechanism of Qingfei touxie fuzheng recipe in the treatment of novel coronavirus pneumonia. Medical Herald. 2020. [Epub ahead of print]

6. Cheng D, Wang W, Li Y, Wu X, Zhou B, Song Q. 51 cases of new coronavirus pneumonia patients with Chinese medicine Lianhua Qingwen curative effect analysis: a multi-center retrospective study. Tianjin Chin Med. 2020. [Epub ahead of print]

7. Yu P, Li Y, Wan S, Wang Y. Observation of therapeutic effect of Lianhua Qingwen granule combined with abidor on mild new coronavirus pneumonia. Chin J Pharm. 2020. [Epub ahead of print]

8. Sun H, Xu F, Zhang L, Wei C, Chen J, Wang Q, et al. Study on clinical efficacy of Lianhua Qingke granule in treatment of mild and ordinary COVID-19. Chin J Experim Prescription. 2020. [Epub ahead of print].

9. Zhang C, Zhang S, Wang W, liang X. Clinical observation of Xuebijing in the treatment of COVID-19. Chin J Hosp Pharm. 2020. [Epub ahead of print].

10. Li X, Wang L, Yan S, Yang F, Xiang L, Zhu I, et al. Clinical characteristics of 25 death cases with COVID-19: a retrospective review of medical records in a single medical center, Wuhan, China. Int J Infect Dis. 2020;94:128-32.

11. Jain A. COVID-19 and lung pathology. Indian J Pathol Microbiol. 2020;63(2):171-2.

12. Leung PC. The efficacy of Chinese medicine for SARS: a review of Chinese publications after the crisis. Am J Chin Med. 2007;35(4):575-81. 